
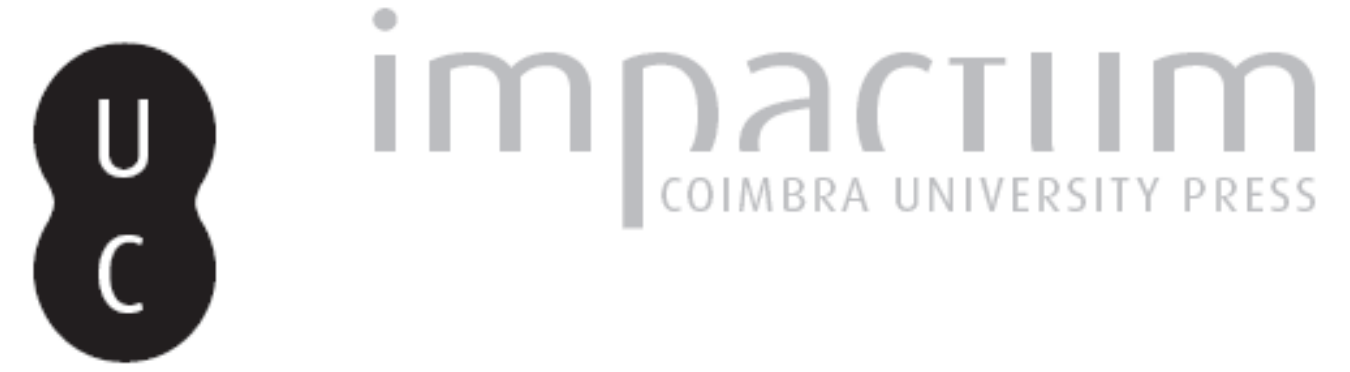

[Recensão a] RODRIGUES, Jorge Nascimento e DEVESAS, Tessaleno - Portugal. 0 Pioneiro da Globalização

Autor(es): $\quad$ Silva, José Manuel Azevedo e

Publicado por: Centro de História da Sociedade e da Cultura

URL persistente:

URI:http://hdl.handle.net/10316.2/39490

DOI:

DOI:http://dx.doi.org/10.14195/1645-2259_11_16

Accessed : $\quad$ 26-Apr-2023 14:11:31

A navegação consulta e descarregamento dos títulos inseridos nas Bibliotecas Digitais UC Digitalis, UC Pombalina e UC Impactum, pressupõem a aceitação plena e sem reservas dos Termos e Condições de Uso destas Bibliotecas Digitais, disponíveis em https://digitalis.uc.pt/pt-pt/termos.

Conforme exposto nos referidos Termos e Condições de Uso, o descarregamento de títulos de acesso restrito requer uma licença válida de autorização devendo o utilizador aceder ao(s) documento(s) a partir de um endereço de IP da instituição detentora da supramencionada licença.

Ao utilizador é apenas permitido o descarregamento para uso pessoal, pelo que o emprego do(s) título(s) descarregado(s) para outro fim, designadamente comercial, carece de autorização do respetivo autor ou editor da obra.

Na medida em que todas as obras da UC Digitalis se encontram protegidas pelo Código do Direito de Autor e Direitos Conexos e demais legislação aplicável, toda a cópia, parcial ou total, deste documento, nos casos em que é legalmente admitida, deverá conter ou fazer-se acompanhar por este aviso.

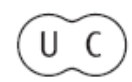




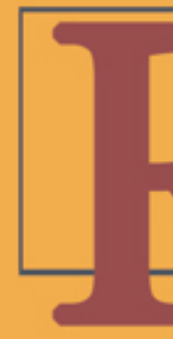

\section{evista de História} da Sociedade e da Cultura

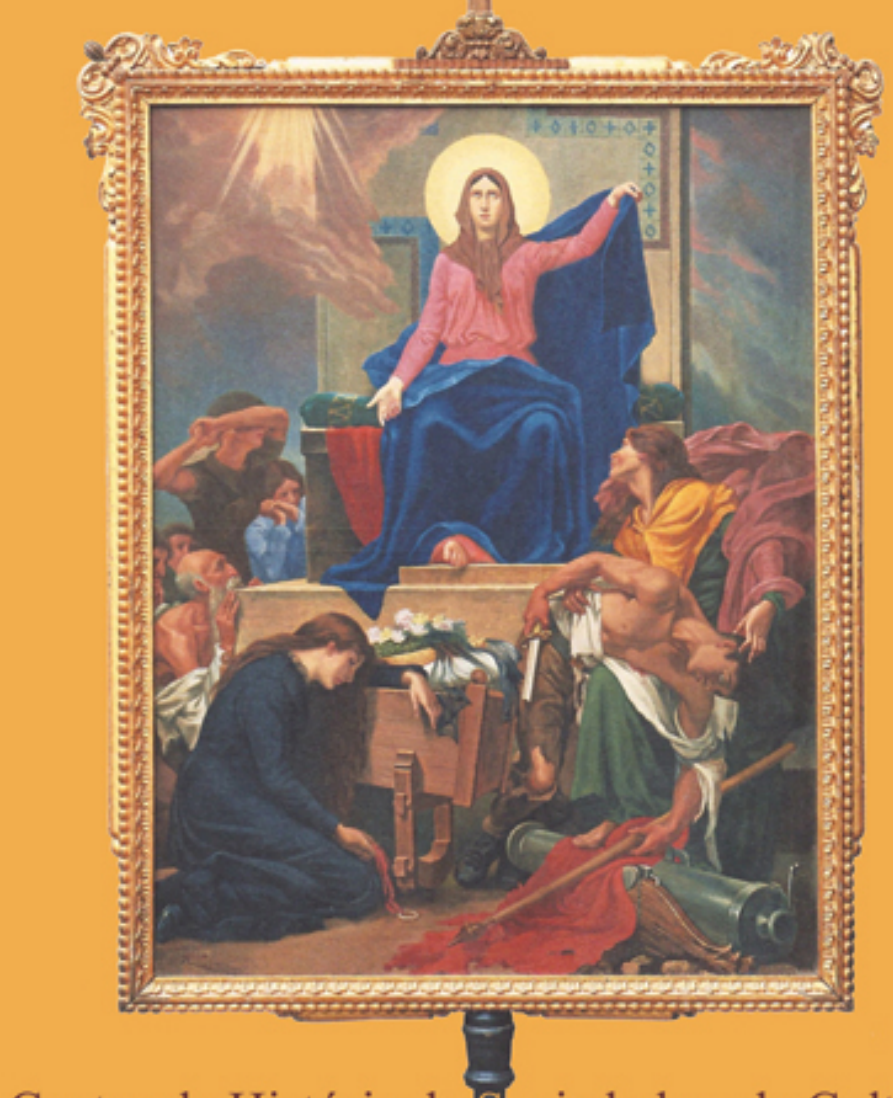

Centro de História da Sociedade e da Cultura Universidade de Coimbra 


\section{Recensões}

\section{RODRIGUES, Jorge Nascimento e DEVESAS, Tessaleno - Portugal. O Pioneiro da Globalização, Vila Nova de Famalicão/Lisboa, Centro Atlântico, 2007, 360 p.}

O conteúdo desta obra, da responsabilidade dos autores em epígrafe, desenrola-se no transcurso de 297 páginas que preenchem dez capítulos, sete dos quais sobre aspectos da História de Portugal, a partir do século XIV. O capítulo I aborda questões teóricas e introdutórias, no oitavo e no último faz-se o ensaio de uma projecção da História até 2030. Um «Portefolio de Outros Olhares» (depoimentos de outros cinco autores que caem fora desta apreciação crítica), ocupa as páginas 299 a 328. Segue-se a bibliografia e as notas (pp. 329-360).

A propósito das notas, diremos que, em nossa opinião, a forma como um livro é concebido, estruturado e organizado deve ter sempre em vista facilitar a vida ao leitor e não ao autor ou ao editor. Ora, ler um livro de 360 páginas com as notas no final obriga o leitor a um jogo de "pingue-pongue" penoso e que lhe corta, mentalmente, o fio sequencial da leitura, problema que se resolve com as clássicas notas infrapaginais.

O mérito desta obra está no seu título (apesar de nada ter de original), ao chamar desde logo a atenção para o facto de que a globalização não é um fenómeno dos nossos dias, como é comum ler-se e ouvir dizer-se; é, sim, fruto de um processo histórico de 500 anos.

Claro que Portugal foi o pioneiro e o principal protagonista da globalização. Em boa verdade, o primeiro passo da globalização, o primeiro «abraço 
à Terra» ${ }^{1}$, deu-se com a viagem de circum-navegação de Fernão de Magalhães e Sebastião del Cano (1519-1522), acontecimento real e simbólico do culminar de um processo de cerca de 100 anos de porfiadas navegações portuguesas que, no dizer de Pierre Chaunu, puseram em contacto os «mundos fechados, compartimentados, encravados». Foi, sem dúvida, o rasgar dos oceanos que pôs em contacto esses mundos e proporcionou o «desencravamento planetário».

Ao tomarmos contacto com o livro e ao lermos o índice, organizado em capítulos, ficámos na dúvida se, para além do pioneirismo português na consumação do primeiro passo da globalização, nos iria ser explicado o processo de 500 anos dessa globalização/mundialização. E ficámos na dúvida, porque, para explicar o processo dos Descobrimentos desencadeado pelos portugueses e a que, na fase final, se juntaram os espanhóis, bastavam algumas páginas, um artigo, um pequeno opúsculo.

O que se constata, ao ler o livro, é que a explicação do pioneirismo português da globalização está implícita e explicada de forma assertiva no título. A explicação do processo histórico dos 500 anos de globalização mal se descortina no decurso das 360 páginas.

Aludindo a um estudo de Michael Bordo, apenas esboçam uma tentativa de explicação da globalização económica em três vagas (pp. 22-26): a primeira vaga consiste nos descobrimentos e na expansão portuguesa; a segunda terá ocorrido a partir do Congresso de Viena (1815), após a derrota de Napoleão, e tornou-se decisiva com a abertura do Canal do Suez (1869); a terceira desencadeou-se «a partir do 'choque' Nixon» (1971), com o abandono do padrão ouro (suspensão da convertibilidade de dólar em ouro) e prosseguiu com a abertura da China (1978), com a queda do Muro de Berlim (1989) e com o início das reformas económicas na Índia (1991). Consideramos este modelo interpretativo manifestamente simplista. Em boa verdade, o processo de globalização é muito mais complexo, como teremos oportunidade de ver mais adiante.

A concepção, a estruturação e a escrita do livro é difusa e confusa. Os autores não definem claramente o objectivo da obra. Ficam-se pelo

1 Veja-se o nosso capítulo do livro (Actas do Colóquio), Filipe II, la Ciencia y la Técnica, Direcção de Enrique Martínez Ruiz, Madrid, Fundesco, 1999, pp. 317-341. 
«ponto de partida» e pela «meta». Lê-se a dado passo: - «Este livro tem um ponto de partida - demonstrar que Portugal foi a primeira potência no Mundo a desencadear o processo hoje conhecido por Globalização, um conceito actualmente tão discutido, e tão mal entendido, nos mais diversos círculos académicos e não académicos». E continuam, sublinhando a pretensa novidade da obra: - «A meta deste livro é mostrar que o pioneirismo português de Quinhentos não é um mito criado por alguns entusiastas dos Descobrimentos. A novidade consiste no facto de que não é baseado apenas em argumentos e factos históricos, como já o fizeram abundantemente com todo o rigor outros autores, que serão referenciados ao longo dos capítulos deste livro, mas também, e principalmente, em modelos de base científica, fazendo uso, inclusive, de princípios físicos e ferramentas matemáticas, como nunca antes foi feito publicamente» (p. 18). O que os autores aqui afirmam é que a História não assenta em modelos de base científica, ou seja, a História não é uma ciência. E esta é, nas próprias palavras dos autores, a grande novidade desta obra.

Mais adiante, os autores afirmam que «o 'coração' deste livro e o seu aspecto distintivo na investigação sobre as Descobertas» está na «análise científica dos dados históricos que comprovam a autenticidade dos argumentos avançados até agora, independentemente de ziguezagues da história e 'buracos negros' provocados por enigmas por esclarecer e desinformação típica da época» (p. 121). E continuam: - «Para que seja possível 'quantificar', ou seja, medir matematicamente, a actividade dos portugueses durante o período das Descobertas, torna-se necessário encontrar uma grandeza de natureza física que possa ser medida. Para tal, escolhemos o número de expedições e campanhas que Portugal executou entre os anos de 1415 (Conquista de Ceuta) e 1625 (expulsão dos franceses do Ceará no Brasil). Foram escolhidos um total de 200 eventos que caracterizaram o movimento de expansão de Portugal neste período, cada um com o objectivo explícito de atingir um ponto geográfico no Planeta, seja para explorá-lo, conquistá-lo ou para construir ali um ponto de apoio estratégico (povoação, feitoria ou fortaleza)» (pp. 121 e 123). Não podemos deixar de exarar aqui a opinião de que tudo isto se nos afigura bastante aleatório.

Este rol dos 200 eventos (data e respectiva descrição) preenche a quase totalidade do capítulo IX. A esta quantificação da história («Cliometria», 
p. 224) de Portugal, no período atrás referido, chamam os autores «intensidade de actividade» (pp. 21, 123, 124 e 130). A nosso ver, não se trata da benéfica quantificação da história e sim da sua matematização, pelo recurso a metodologias e modelos matemáticos e físicos.

É óbvio que a história se tem enriquecido com a utilização de dados quantificáveis, nomeadamente séries de produções, de preços, de salários, de livros de receitas e despesas das instituições, de balanços de empresas... Mas não nos parece aceitável «escolher» factos históricos e quantificá-los para medir a «intensidade de actividade» de um povo, muito menos com a finalidade que se lhes atribuiu.

Os autores pretendem revolucionar o "fazer a história", o "ofício do historiador", através da aplicação da metodologia dos saberes das suas áreas de formação académica e profissional: editor de portais e de blogues de geopolítica na Web, jornalista de temas de gestão e tecnologia, editor e co-autor de livros, no caso do primeiro autor; o físico e o engenheiro de materiais, no caso do segundo (p. 26 e $2^{\text {a }}$ badana do livro).

A novidade desta obra está, para os autores, na aplicação à construção histórica da análise quantitativa e da metodologia científica da física, segundo a qual, como é sabido, «as mesmas causas produzem sempre os mesmos efeitos, quando postas nas mesmas circunstâncias». Dito de outro modo, os autores ousam aplicar às ciências humanas, concretamente à História, as metodologias das ditas ciências exactas. E consideram que a grande inovação deste livro está na aplicação dessa fórmula à História. É este «o aspecto inovador das abordagens» feitas no decurso do livro, anunciadas na introdução (p.18) e a «nova metodologia para a análise histórica» (p. 21).

Por outro lado, por exigência lógica das suas metodologias, consideram que a história se repete (pp. 222, 223, 224 e 257). Chegam mesmo a afirmar que «o velho dictum de que 'a História se repete' é senso comum entre leigos e historiadores» (p. 222). Preclaros autores da obra objecto desta recensão, por favor, deixem os historiadores em paz! Para o historiador que se preze, a História nunca se repete.

Daqui, desta sua visão metodológica, decorre uma abordagem determinista da história. De resto, munidos deste determinismo, partem para «cenários futuros» de elaboração histórica até 2030 (pp. 229-251 e 285-297). E o mais estranho é que, da análise de 200 eventos da História de 
Portugal, os autores decidam avançar deterministicamente para a projecção da História Universal até essa data.

Ora, o determinismo é a negação da História. Mais, é anti-histórico.

No final da obra, os autores asseveram que «a construção do futuro de uma nação deve seguir o algoritmo básico da construção dos sistemas: PLANEAR. DECIDIR, EXECUTAR. E, a rematar, dizem que «os diferentes capítulos deste livro tentam mostrar como, dentro desta óptica, analisando a história de Portugal, podemos extrair as lições necessárias, positivas e negativas, para desenhar um cenário não apenas desejado, mas realizável durante o período crítico de transição a vivenciar nas próximas décadas». Aqui está a razoabilidade das apreciações críticas que atrás deixámos expressas.

Poderá argumentar-se que a interdisciplinaridade é enriquecedora para qualquer ciência. É verdade que sim. Mas a prática interdisciplinar tem de ser usada de forma parcimoniosa, criteriosa e com bom-senso. Consiste nos contributos que uma ciência ou uma área do saber pode colher (pedir emprestado) das outras ciências e não no "afogar" essa ciência, neste caso a História, com metodologias, princípios, modelos e conceitos inadequados, "transportados" de outras ciências, na situação vertente, a Física e a Matemática.

Aplaudimos a forma como foram analisadas e desmontadas, pelos autores da obra em apreço, as fantasias do comandante de submarinos inglês David Menzies, autor do livro intitulado 1421-O Ano em que a China Descobriu o Mundo², Lisboa, Publicações D. Quixote, 2004, 446 p.

Concluída a apreciação crítica do livro Portugal. O Pioneiro da Globalização, achamos oportuno e desejável fazer uma síntese do nosso pensamento sobre a tão propalada globalização/mundialização, a fim de demonstrar que a maior parte das 360 páginas poderia ter sido utilizada de forma bem mais útil se os autores tivessem enveredado por esse objectivo estratégico, com modelos e metodologias adequadas.

2 Veja-se a recensão crítica (desmontagem, desconstrução) a este livro, por nós publicada em Revista de História da Sociedade e da Cultura, Coimbra, Palimage - Centro de História da Sociedade e da Cultura, 2005, pp. 237-243. 
Convirá começar por esclarecer que a globalização não é um fenómeno dos nossos dias, das últimas décadas, criado pela cibernética, mais concretamente com os computadores e com a Internet. Não. A globalização tem uma história de seis séculos, dividida em dois períodos e dois processos distintos.

O primeiro período corresponde ao processo de um século dos Descobrimentos Marítimos que culminou com a viagem de circum-navegação de Fernão de Magalhães. Foi o primeiro abraço à Terra. Estava dado o primeiro passo da globalização. Rasgados os oceanos, ficou aberta a possibilidade de pôr em contacto os continentes e os espaços insulares.

O segundo período compreende o processo evolutivo da História da Humanidade verdadeiramente Universal, nos últimos cinco séculos. É como que tentar avaliar a "distância" da evolução histórica do Mundo globalizado, desde o feito de Magalhães até aos nossos dias.

Ora, estudar e compreender os 500 anos de globalização/mundialização é lidar com um processo extremamente complexo, uma vez que ele envolve todas as componentes e dinamismos da realidade histórica, actuando de forma transversal e articulada, nomeadamente: a política, a economia, a sociedade, as ciências, as técnicas, a cultura, a religião, os meios de transporte, a informação. Retenha-se que os referidos dinamismos aparecem-nos cadenciados a ritmos inconstantes, mas tendencialmente acelerados.

É evidente que não cabe no âmbito de uma recensão a abordagem de todos os aspectos da globalização. Vamos, por isso, centrar-nos nos dois últimos, nos meios de transporte e na informação. Mais concretamente, vamos procurar captar a evolução das mudanças de ritmo e da aceleração da velocidade na circulação das pessoas, dos bens/mercadorias e da informação a nível do globo, nos últimos 500 anos. Com a globalização, ganha sentido a ideia de que as distâncias se medem em unidades de tempo e não em quilómetros ou milhas.

Comecemos pelos transportes marítimos. A lentidão dos barcos antigos e medievais foi súbita e largamente ultrapassada pela ligeira caravela, nas décadas de 30/40 do século XV. Claro que as próprias caravelas, quer a latina, quer a redonda, foram sendo aperfeiçoadas, aumentando a sua velocidade. Por vezes, no funcionamento da Carreira da Índia, saía de Lisboa uma caravela várias semanas (por vezes, um a dois meses) depois da partida da armada, com cartas régias, mensagens ou outros dados urgentes, e conseguia 
juntar-se a ela antes da travessia do Índico. O mesmo acontecia nas viagens de regresso. Era a chamada caravela de aviso.

As próprias naus, galeões e outros tipos de navios, principalmente a partir dos finais do século XVI, foram ganhando velocidade, com o aumento da mastreação e do velame, os "cavalos-força" das embarcações. Quando, nos princípios do século XIX, entraram em acção os navios de vapor ${ }^{3}$, os céleres veleiros irão disputar-lhes, por longo tempo, a primazia da velocidade. Claro que os navios de vapor acabarão por impor-se, até porque tinham a vantagem de poderem traçar rotas em linha recta. Seguir-se-ão os navios e os submarinos movidos a motor diesel e eléctricos e, mais tarde, a energia atómica ou nuclear.

Os transportes terrestres evoluíram a um ritmo mais lento. Depois das estradas romanas, muitas das quais continuaram em funcionamento, a abertura de estradas, caminhos e veredas de terra batida foram permitindo a penetração nos espaços terrestres, até à chegada das estradas de macadame (princípios do século XIX), seguindo-se os pisos betuminosos, que muito beneficiaram a circulação do automóvel (finais do século XIX). Nas últimas décadas, a rede de auto-estradas e o constante aperfeiçoamento técnico dos veículos automóveis tem permitido um enorme avanço no aumento da velocidade da circulação rodoviária e da segurança.

Convém não esquecer que, até ao século passado, a navegação fluvial foi importante na penetração dos espaços terrestres. Tomemos, como exemplo mais significativo, as grandes canoas da bacia amazónica e, no caso português, o barco rabelo do Douro, a barca serrana do Mondego ou o bote do pinho do Tejo.

Ainda no domínio dos transportes terrestres, há que dar o devido lugar ao comboio que rapidamente se tornou num meio de transporte de "massas". O primeiro veículo deste tipo começou a circular na Inglaterra, em 1825, e, a partir daí, tendeu a implantar-se, a bom ritmo, em todo o Mundo, sendo necessário construir extensas e complexas redes ferroviárias. Claro que a aceleração da velocidade dos transportes ferroviários foi uma constante,

3 O primeiro navio de vapor foi construído na Escócia, em 1802. O escocês James Watt tinha concebido e desenvolvido a máquina a vapor na última parte do século XVIII. Veja-se Enciclopédia FOCUS, vol. 4, pp. 642 e 643. 
há quase 200 anos. Tal tem a ver com a fonte de energia utilizada e com o tipo de carris, desde o comboio a vapor (a lenha e carvão), ao mecânico a diesel até ao eléctrico que culminou com o chamado TGV (transporte de grande velocidade). Não esqueçamos, ainda, na circulação urbana e suburbana, a importância dos cómodos e rápidos "metropolitanos".

Passemos aos transportes aéreos. Desde os tempos helénicos e míticos de Dédalo e de seu filho Ícaro que o homem aspirava voar como as aves. Terá de esperar pelo século XVIII, também pela mão dos portugueses. Em 8 de Agosto de 1709, um balão, cheio de ar quente (a célebre passarola, inventada pelo padre Bartolomeu de Gusmão), voou desde o castelo de S. Jorge até ao Terreiro do paço, perante numerosa assistência e a presença de D. João V. Seguiram-se os balões de hidrogénio, os dirigíveis, os hidroaviões e os aviões. A velocidade irá aumentando vertiginosamente, desde o planador (1894), o primeiro avião a motor (1903), o avião a jacto (1940), o avião supersónico $(1953)^{4}$. E o aumento das dimensões, da comodidade e da velocidade não parou de se intensificar até aos nossos dias.

Depois da Segunda Guerra Mundial, americanos e russos lançaram-se na disputa da corrida interplanetária da chegada à Lua e no sonho de ir a Marte. Nasce assim a navegação astronómica ou cosmonáutica. De grande importância são os satélites artificiais de comunicações, a que voltaremos mais adiante.

Todos os tipos de transportes de que falámos até aqui põem em circulação, em menor ou maior distância, nomeadamente a nível planetário, pessoas, bens/mercadorias e notícias/informações. Preocupámo-nos em vincar as mudanças de ritmo, as dinâmicas e a aceleração da velocidade. Vamos concluir este trabalho com a circulação, apenas, da palavra (escrita ou falada) e da imagem. No fundo, trata-se da transmissão de mensagens, sejam elas de que tipo for.

Vejamos os diferentes tipos de informação/comunicação à distância.

O tipo mais antigo é a telegrafia sem fios, inventada em 1844 por Samuel Morse. Consiste na transmissão e gravação de mensagens através de sinais telegráficos sistematizados num código (o código morse) que tem por base apenas dois sinais elementares: o ponto e o traço.

\footnotetext{
4 Veja-se Enciclopédia FOCUS, vol. 1, pp. 330-337.
} 
Outro tipo de transmissão de comunicações/informações que, a ritmos inconstantes, mas acelerados, se globalizou, a partir da sua invenção por Graham Bell, em 1876, foi o telefone (telegrafia com fios). O telex e o faxe assentam em idênticos princípios técnicos, mas, em vez da voz, transmitem mensagens escritas.

A grande revolução da comunicação à distância foi a descoberta das ondas electromagnéticas e a sua propagação à velocidade da luz, por Heinrich Hertz, em 1888.

As chamadas ondas hertzianas tornaram possível a Guglielmo Marconi (1896) a transmissão de mensagens, através da comunicação sem fios. Tal conduziu à invenção e constante aperfeiçoamento da radiocomunicação ou radiotelefonia que assenta na sincronização da frequência entre o aparelho emissor e o receptor.

Quatro décadas mais tarde (1936), nascerá, em Londres, a radiotelevisão. A televisão assenta nos mesmos princípios da radiotelefonia. A novidade está, fundamentalmente, na câmara de captação de imagens e na associação da imagem ao som. As iniciais emissões de imagens a preto e branco darão lugar às emissões a cores, ocorridas nos Estados Unidos, a partir de 1950. Como é sabido, a evolução técnica da televisão não tem parado até aos nossos dias.

A última grande tecnologia de comunicação por meio das ondas hertzianas é o telemóvel que rapidamente se difundiu (democratizou) por todo o Mundo. Dir-se-ia que as capacidades e funcionalidades dos mais recentes modelos de telemóveis resultam da fusão dos princípios tecnológicos da radiotelefonia e da televisão.

Vamos concluir com a inevitável referência aos computadores, as chamadas novas tecnologias de informação. Depois da Segunda Grande Guerra Mundial, a ciência cibernética desenvolveu-se de modo galopante. Em 1953, ficou concluída, na Suécia, a construção do primeiro computador, o célebre Besk. A partir de então, o ritmo e a velocidade de evolução desta tecnologia tem sido tal que, cada novo modelo, fica obsoleto em poucos anos, passando a ser mera "peça de museu". Não há dúvida que os computadores electrónicos, servidos pela Internet, abriram as chamadas auto-estradas da informação, revolucionaram a gestão estratégica das empresas, das pessoas consideradas individualmente e da sociedade em geral. 
Todas as tecnologias de transportes e de comunicações continuarão a evoluir em busca da rapidez, da velocidade, tal como os antigos veleiros de que falámos atrás. Em boa verdade, a evolução do processo de globalização mede-se pela velocidade da transmissão das comunicações. Em termos metafóricos, podemos dizer que o alfa e o ómega desta evolução está entre a diferença dos três anos que demorou a viagem de circum-navegação de Fernão de Magalhães e a possibilidade da transmissão da comunicação/ /informação, através de todo o Mundo, em tempo quase real. Ainda falta resolver o "quase".

\section{José Manuel Azevedo e Silva}

Universidade de Coimbra e Centro de História da Sociedade e da Cultura da UC

jazevedosilva@gmail.com

\section{MARTINS, Miguel Gomes - De Ourique a Aljubarrota. A Guerra na Idade Média. Lisboa, Esfera dos Livros, 2011 (435 pgs.).}

A prestigiada editora A Esfera dos Livros publicou recentemente a obra De Ourique a Aljubarrota. A Guerra na Idade Média. O autor é Miguel Gomes Martins, Licenciado em História pela Faculdade de Letras de Lisboa, Mestre e Doutor em História da Idade Média pela Universidade de Coimbra.

Trata-se de um livro grande (435 pgs.) e, diga-se desde já, de um grande livro. Mais um com a assinatura da Esfera, uma das editoras que mais tem feito pela História no mercado livreiro português. Para começar, para quem gosta de livros, esta obra é um belo objecto. Tem um formato bastante simpático (16 x 23,5 cm), uma capa bonita (reprodução de uma iluminura da Bíblia da Pierpont Morgan Library, de Nova Iorque), papel de boa qualidade, uma mancha tipográfica que assegura uma leitura confortável (e com margens suficientes para anotações), mapas e esquemas de batalha (a preto-e-branco) de boa qualidade e, ainda, um caderno central de extra-textos a cores. Gralhas, há muito poucas, mesmo para quem gosta de lhes fazer caça.

Do ponto de vista do conteúdo, De Ourique a Aljubarrota. A Guerra na Idade Média é um livro que revela um excelente compromisso entre 